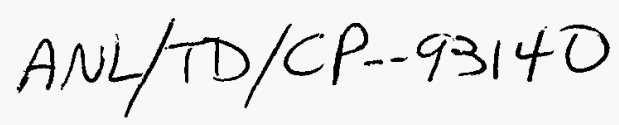

CONF- -971149

\title{
Predicting Threshold Laser Beam Irradiances for Melting and Welding
}

\author{
K. H. Leong, H. K. Geyer, K. R. Sabo and P. G. Sanders \\ Technology Development Division \\ Argonne National Laboratory \\ Argonne Illinois 60439 \\ USA
}

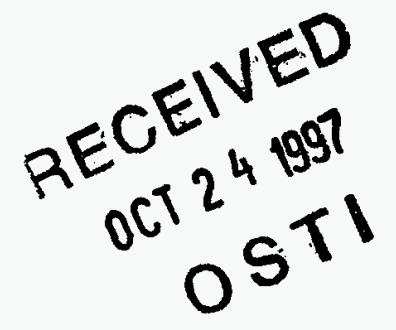

The submitted manuscript has been authorized by a contractor of the U. S. Government under contract No. W-31-109-ENG-38. Accordingly, the U. S. Government retains a non-exclusive, royalty-free license to publish or reproduce the published form of this contribution, or allow others to do so, for U. S. Government purposes.

\begin{abstract}
A model based on conservation of energy for a moving heat source incident on a flat plate is used to predict the threshold laser beam irradiance required to initiate melting on a metal surface. With the use of a nondimensional variable and its solution, the threshold irradiance can be predicted with the use of a simple equation that is a function of the absorptivity of the surface, thermal conductivity of the metal, temperature increase for melting, diameter of the laser beam at the surface and the nondimensional variable value for the ratio of the thermal diffusivity of the metal to the product of the beam diameter and velocity used. Laser beam irradiances exceeding these predicted values are required for welding. The model predictions are validated with experimental results of beam irradiances required for welding different metals.
\end{abstract}

Keywords: lasers, threshold irradiance, laser beam welding

\section{Introduction}

Laser beam welding has become the preferred joining method for many manufacturing applications that require high speed and precision with low heat effects. In the automotive area, the process parameters required for the production of sound welds in steel are well understood. In the case of aluminum, application of these process parameters developed for steel have not produced good welds [1]. More recent work with a better fundamental understanding of the welding process showed the need for a higher irradiance beam to affect welds on aluminum alloys [2]. It is generally understood that the high reflectivity or poor absorptivity of aluminum alloys for the laser radiation together with the high thermal conductivity increases the required threshold irradiance. Experimental attempts to correlate the threshold irradiance with the thermal conductivity of the alloy show no clear trends $[2,3,4]$. Rapp et al. showed that alloying element volatility also affected the threshold irradiance [3]. However, the published literature does not indicate a thorough comprehension of the parameters affecting the threshold irradiance and the establishment of a consistent keyhole. Factors contributing to this problem include confusion on the effects of basic physical mechanisms, and a lack of accurate information on absorptivities and thermodynamic property values at high temperatures.

In process development, a simple guide or predictive method that provides qualitative trends is often more practical and useful than a complex model that is a function of many variables. In addition, a nondimensional predictive tool is of more general use for application to different metals and alloys. The intent of this paper is to present a simple equation for the general prediction of

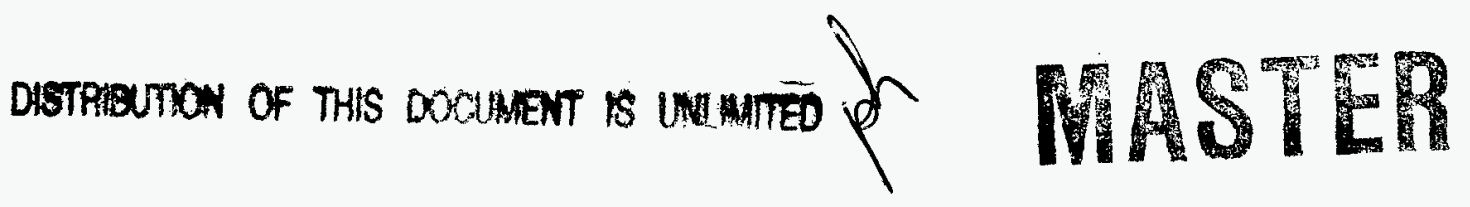




\section{DISCLAIMER}

This report was prepared as an account of work sponsored by an agency of the United States Government. Neither the United States Government nor any agency thereof, nor any of their employees, make any warranty, express or implied, or assumes any legal liability or responsibility for the accuracy, completeness, or usefulness of any information, apparatus, product, or process disclosed, or represents that its use would not infringe privately owned rights. Reference herein to any specific commercial product, process, or service by trade name, trademark, manufacturer, or otherwise does not necessarily constitute or imply its endorsement, recommendation, or favoring by the United States Government or any agency thereof. The views and opinions of authors expressed herein do not necessarily state or reflect those of the United States Government or any agency thereof. 
threshold laser beam irradiance for the onset of melting. These predicted irradiance values form the lower bound of irradiance values necessary for laser beam welding and aid the user in determining the required beam parameters for effective processing.

\section{Surface melting model}

The model configuration is that of a laser beam focussed onto a flat metal plate moving at a constant velocity. The equivalent problem is that of a finite heat source travelling at constant velocity on the surface of a plate. We seek to find a solution that will determine the required beam irradiance to initiate melting given the beam diameter at the surface and the thermophysical properties of the metal. The equation for the conservation of energy in the reference frame of the beam is

$$
\nabla \cdot(k \nabla T)+\rho c_{p} v \frac{\partial T}{\partial y}=0
$$

where $\mathrm{k}$ is the thermal conductivity of the metal, $\rho$ is the density, $c_{p}$ is the specific heat and $v$ is the speed of the plate in the y coordinate.

Letting the boundary conditions be zero heat loss through the top surface and ambient temperature on the sides and bottom surface of the plate it is possible to nondimensionalize Eqn. (1) by redefining the variables as

$$
\begin{aligned}
& x^{\prime}=x / d \\
& y^{\prime}=y / d \\
& z^{\prime}=z / d \\
& T=T_{0}+\frac{I_{a} d}{k} J\left(x^{\prime}, y^{\prime}, z^{\prime}\right)
\end{aligned}
$$

where the new variable $\mathrm{J}$ satisfies

$$
\frac{1}{\mathrm{~d}} \nabla \cdot(\mathrm{k} \nabla \mathrm{J})+\rho \mathrm{c}_{\mathrm{\rho}} \mathrm{v} \frac{\partial \mathrm{J}}{\partial \mathrm{y}^{\prime}}=0
$$

and the $\nabla$ operator now refers to the primed coordinates, $\mathrm{d}$ is the diameter of the beam at the top surface, $I_{a}$ is the absorbed irradiance, and $T_{0}$ is the ambient temperature. The boundary conditions for $\mathrm{J}$ are

$$
\begin{aligned}
& \frac{\partial \mathrm{J}}{\partial \mathrm{z}^{\prime}}=1 \quad \text { at the top surface where the beam impinges, }=0 \text { otherwise. } \\
& \mathrm{J}=0 \quad \text { at surfaces far from the beam. }
\end{aligned}
$$

The beam profile is assumed to be top hat and hence the plane of symmetry is along $x=0$. The maximum temperature is given by

$$
\mathrm{T}_{\max }=\mathrm{T}_{0}+\frac{\mathrm{I}_{\mathrm{a}} \mathrm{d}}{\mathrm{k}} \mathrm{J}_{\max }
$$


Since the melting point of the metal is known, Eqn. 6 can be used to predict the beam irradiance required for initiating melting,

$$
I_{m}=\frac{k\left(T_{\text {melt }}-T_{0}\right)}{A d J_{\max }}
$$

where $A$ is the absorptivity of the surface. $J_{\max }$ can be obtained by solving Eqn ( 3 ) for the case of an infinitely thick metal sheet. However, the 3-D numerical solution requires substantial computational time. It was found that a good approximation can be obtained for a finite size plate of 10 beam diameters thickness and a horizontal extent of 35 beam diameters in the forward direction and 100 beam diameters in the opposite direction. Doubling the dimensions did not produce more than $1 \%$ change in the value of $\mathrm{J}_{\max }$. A finite size plate is also a better representation of the experimental conditions during welding. For any metal, the minimum beam irradiance required for melting can then be estimated using the thermophysical properties and the $\mathrm{J}_{\max }$ curve shown in Fig. 1. The thermal diffusivity $\alpha=k /\left(\rho c_{\rho}\right)$.

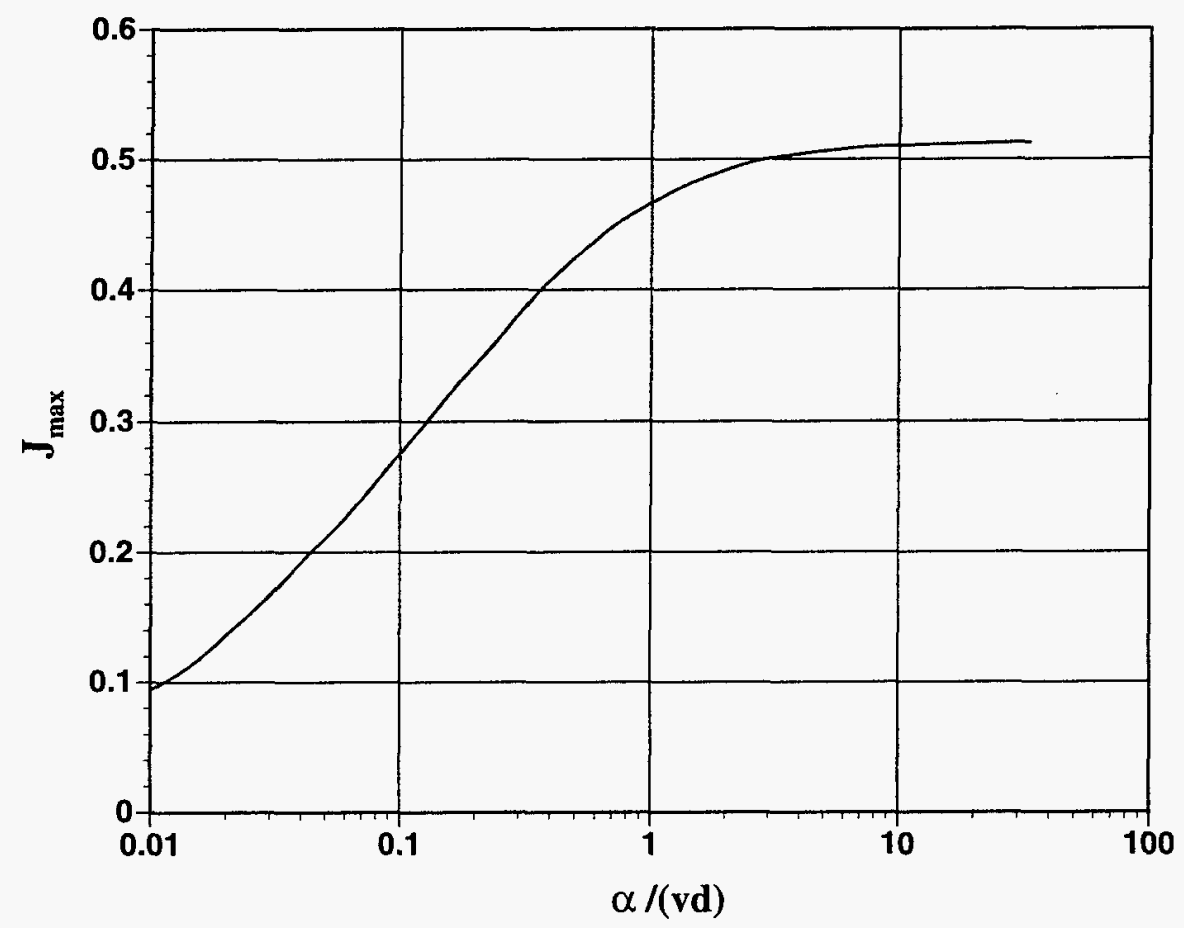

Figure 1. Values of $\mathrm{J}_{\max }$ computed from Eqn. (5) as a function of the ratio of the thermal diffusivity to the product of the beam velocity and diameter.

At slow welding speeds or small focussed beam diameter where $\alpha /(v d) \geq 10$, the diffusivity of the material dominates and $\mathrm{J}_{\max }$ has a limiting value of approximately 0.52 . For the range of metals, welding speeds and beam diameters considered, $\alpha /(\mathrm{vd})<10$. From a physical viewpoint, Eqn. (5) has the expected effect of the different thermophysical properties. Higher thermal conductivities, melting points and smaller beam diameters will require higher irradiances.

Plasma effects will increase the beam irradiance requirements. Keyhole welding requires irradiance values higher than for melting. Values of the thermal diffusivity and conductivity are available for most metals and alloys $[5,6]$. The beam diameter can be measured precisely using 
beam analyzers such as the Prometec laser beam analyzer. Absorptivities can be computed for metals using the complex refractive index values [7]. However, the absorptivity values are affected by the surface condition and temperature $[7,8,9]$. Nevertheless, this simple equation should provide relatively good lower bound values.

\section{Model validation}

The utility of Eqn. (5) is examined using published data on laser welding of different metals. Table 1 lists the values used for the thermophysical properties of the metals to determine $\mathrm{I}_{\mathrm{m}}$. The values used for the absorptivity is for the pure and polished metal. For actual conditions encountered during laser beam welding, the absorptivities are expected to be higher due to oxide layers and surface roughness [11]. The solidus temperature is used for the melting point for the aluminum alloys [12]. Thermal conductivities at the solidus temperature for aluminum alloys range from $150 \mathrm{~W} \mathrm{~m}^{-1} \mathrm{~K}^{-1}$ for 5000 series alloys to $220 \mathrm{~W} \mathrm{~m}^{-1} \mathrm{~K}^{-1}$ for AA1 100 [6]. The metals in Table 1 covers a large range in values of the parameters in Eqn. (5).

\begin{tabular}{||l|c|c|c|c|c||}
\hline & $\alpha\left(\mathrm{cm}^{2} \mathrm{~s}^{-1}\right)$ & $\mathrm{k}\left(\mathrm{W} \mathrm{m} \mathrm{m}^{-1}\right)$ & $\mathrm{T}_{\text {melt }}(\mathrm{K})$ & $\mathrm{A}-10.6 \mu \mathrm{m}(\%)$ & $\mathrm{A}-1.06 \mu \mathrm{m} \%)$ \\
\hline aluminum & 0.68 & 210 & 933 & 5 & $\sim 11$ \\
\hline copper & 0.79 & 330 & 1357 & 5 & \\
\hline iron & 0.063 & 30 & 1811 & 10 & \\
\hline vanadium & 0.11 & 50 & 2202 & 5 & $\sim 45$ \\
\hline
\end{tabular}

Table 1. Thermophysical properties at the melting point of metals that were laser beam welded. Data from [5-10]. The absorptivities for aluminum are predicted values from [10]. The absorptivities for vanadium were derived from the complex refractive index values given by Guizzetti and Piaggi [11] and adjusted for the melting point.

It should be noted that laser beam absorption with a plasma and keyhole during welding tends to be substantially higher than that encountered during laser heating of a metal. However, higher threshold irradiance for welding than melting is required to melt and vaporize metal to form a keyhole $[7,8,9]$. Consequently, the use of the data from Table 1 and the condition for melting in Eqn. (5) will generate irradiances that are lower bound values of those required for welding.

The data for keyhole welds using $\mathrm{cw}$ lasers are derived from published literature and the authors' work (Table 2). The value of $\mathrm{v}$ ranges from 1.0 to $18.3 \mathrm{~cm} \mathrm{~s}^{-1}$ and $\mathrm{d}$ ranges from 160 to $500 \mu \mathrm{m}$. Weld penetration varied from 1.0 to $2.7 \mathrm{~mm}$. There is some uncertainty in comparing the irradiances used for welding. Higher irradiance is required for deeper penetration and not all the data is for the same penetration. Some of the references specify the location of the focus (usually at the surface) but others do not. Some may have located the beam focus above the surface resulting in a higher required irradiance than at the surface. As predicted by Eqn. (7), the irradiances computed for melting are lower than the irradiances used for welding. This is evident in Fig. 2 where the ratio of the irradiance used for keyhole welding to the predicted irradiance for melting is plotted as a function of the latter parameter. All data values is above 1.0 except for the copper data. This discrepancy is small as an increase in the absorptivity assumed for copper from $5 \%$ to $6 \%$ would increase the ratio to one. The $5 \%$ value is for pure copper. The presence of an oxide layer or roughness will increase the absorptivity substantially. 


\begin{tabular}{|c|c|c|c|c|c|}
\hline & $\mathrm{v}\left(\mathrm{cm} \mathrm{s}^{-1}\right)$ & $\mathrm{d}(\mu \mathrm{m})$ & penetration(mm) & $I_{\text {melt }}\left(10^{6} \mathrm{~W} \mathrm{~cm}^{-2}\right)$ & $I_{\text {weld }}\left(10^{6} \mathrm{~W} \mathrm{~cm}^{-2}\right)$ \\
\hline \multicolumn{6}{|l|}{ Nd:YAG } \\
\hline$[17]-6000$ & 13.33 & 450 & 1.0 & 0.91 & 1.6 \\
\hline [18]-6082 & 18.33 & 300 & 1.0 & 1.38 & 2.0 \\
\hline$[20]-5754$ & 6.35 & 600 & 2 & 0.28 & 0.82 \\
\hline \multirow[t]{3}{*}{ vanadium } & 3.39 & 500 & 1.6 & 0.11 & 0.71 \\
\hline & 1.02 & 500 & 2.2 & 0.10 & 0.71 \\
\hline & 0.677 & 500 & 2.4 & 0.098 & 0.71 \\
\hline \multicolumn{6}{|l|}{$\mathrm{CO}_{2}$} \\
\hline [2]-aluminum & 8.33 & 360 & 1.0 & 1.5 & 3.5 \\
\hline [3]-copper & 8.33 & 220 & 1.0 & 6.3 & 5.2 \\
\hline copper & 4.23 & 320 & 2 & 4.3 & 5.5 \\
\hline steel & 12.7 & 400 & 0.8 & 0.41 & 2.1 \\
\hline 12SR stainless & 2.22 & 270 & 2 & 0.3 & 1.5 \\
\hline vanadium & 12.7 & 408 & 1 & 1.4 & 3.2 \\
\hline [4]-1100 & 1.67 & 240 & 1.0 & 2.2 & 3.1 \\
\hline [4]-2017 & 1.67 & 232 & 1.0 & 1.7 & 2.7 \\
\hline [13]-2024 & 13 & 160 & 1.0 & 2.0 & 4.7 \\
\hline [4]-7NO1 & 1.67 & 238 & 1.0 & 1.7 & 2.9 \\
\hline [4]-5083 & 1.67 & 220 & 1.0 & 1.6 & 2.3 \\
\hline 5182 & 16.9 & 400 & 0.98 & 0.89 & 2.1 \\
\hline$[14]-5182$ & 13 & 160 & 1.0 & 2.1 & 4.7 \\
\hline$[15]-5000 \mathrm{x}$ & 8.33 & 250 & 1.0 & 1.4 & 3.5 \\
\hline$[16]-5754$ & 6.5 & 500 & 1.5 & 0.74 & 2.8 \\
\hline$[2]-6000 x$ & 8.33 & 360 & 1.0 & 1.3 & 2.0 \\
\hline$[16]-6016$ & 10 & 272 & 1.0 & 1.6 & 3.7 \\
\hline [19]-6009 & 12.7 & 250 & 2 & 1.8 & 11.2 \\
\hline$[18]-6082$ & 18.33 & 300 & 1.0 & 1.5 & 2.0 \\
\hline \multirow[t]{3}{*}[14]{-6082} & 13 & 160 & 1.0 & 2.7 & 4.7 \\
\hline & 18 & 200 & 1.8 & 2.2 & 9.9 \\
\hline & 8 & 300 & 2.7 & 1.5 & 4.4 \\
\hline
\end{tabular}

Table 2. Irradiances computed for melting for different process conditions, metals and $\mathrm{cw}$ lasers. The process conditions and beam irradiances for welding used are from the authors' data and the references listed. 


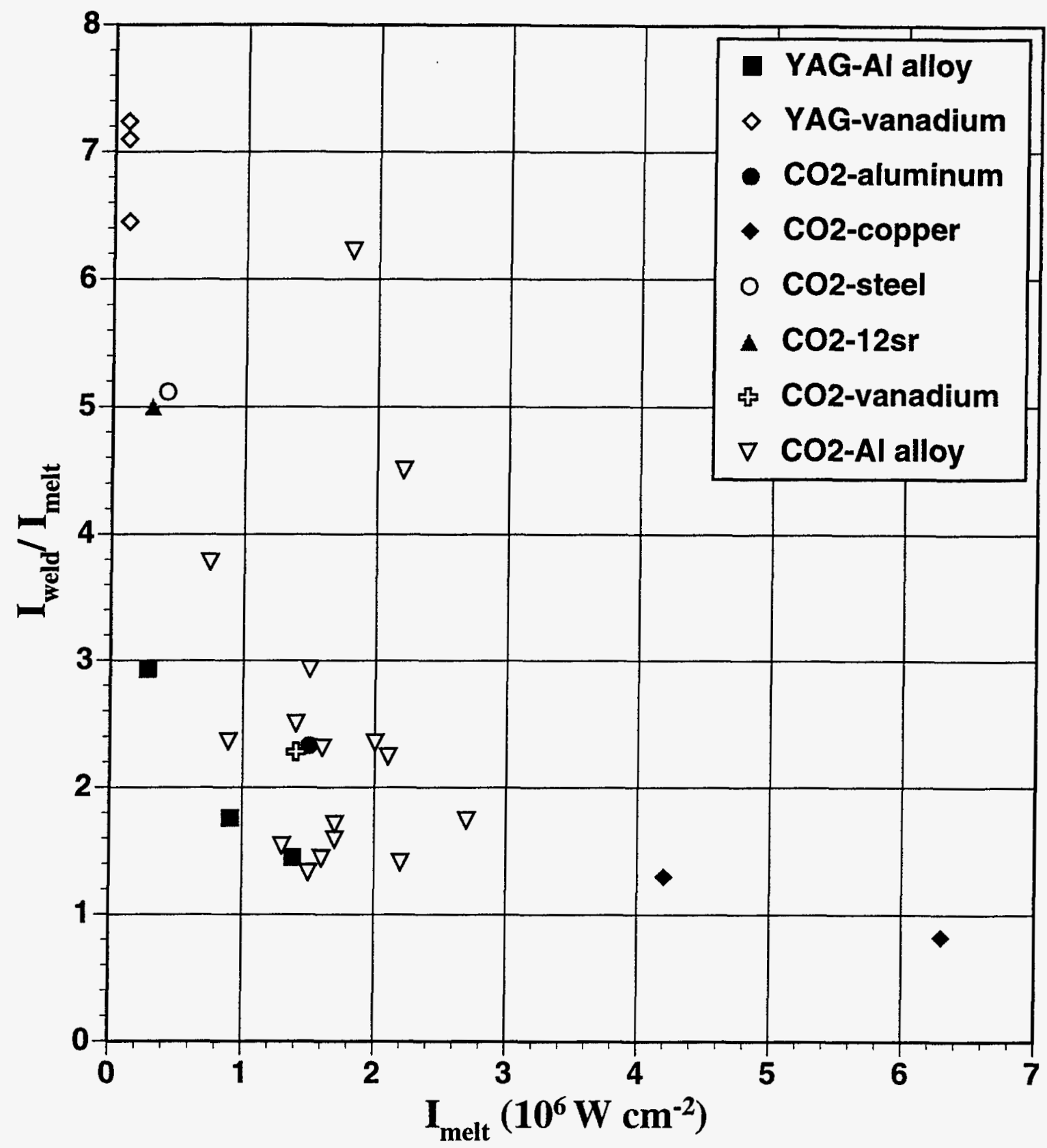

Figure 2. Ratio of irradiance used for welding to irradiance computed for melting for different metals and alloys as a function of the irradiance computed for melting. Data derived from Table 2.

The data in Fig. 2 exhibits a trend of higher values of $I_{\text {weld }} / I_{\text {melt }}$ for lower values of $I_{\text {melt }}$. There is considerable scatter in the data for aluminum alloys. As mentioned previously irradiances used for welding are affected by weld penetration and speed in addition to beam focus position. Deeper penetration at constant weld speed will also require higher irradiance. Irradiance requirements will also be affected by the optics used if the depth of focus is shallower than the penetration required. Regardless of the process parameters used, a minimum irradiance is required to maintain the plasma and keyhole. Keyhole welding would then dictate a minimum irradiance that will depend on the wavelength and the materials properties. Data available indicate a value of $105 \sim 10^{6} \mathrm{Wcm}^{-2}$ 
to maintain the plasma and keyhole [7]. Hence, the ratio of $I_{w e l d}$ to $I_{\text {melt }}$ would tend to increase for lower $\mathrm{I}_{\text {melt }}$ values particularly when they are $<106 \mathrm{~W} \mathrm{~cm}^{-2}$.

\section{Conclusions}

The solution of the heat flow equation for a moving finite heat source on a flat plate results in a simple algebraic equation which predict the minimum laser beam irradiance required for the onset of melting. This melting threshold irradiance gives a lower bound of the irradiance required for welding. For the data examined in the literature, the irradiances used for welding different metals and alloys under a wide range of beam diameters and welding speeds are within a factor of 10 times the melting threshold irradiance predicted. Closer scrutiny of the process conditions, such as depth of focus and the location of the focus, allow a closer approximation of the required irradiance for the penetration needed. Hence this simple equation for the prediction of the melting threshold irradiance can serve as a pragmatic guide for the irradiance required to weld a particular metal or alloy with a given set of process parameters.

\section{Acknowledgements}

This work was supported in part by the U.S. Department of Energy, Office of Energy Research Laboratory Technology Research Program and the Office of Transportation Technologies. Ken Sabo was a Laboratory-Graduate Participant in a program administered by the Argonne Division of Educational Programs with funding from the U.S. Department of Energy. The authors thank Tom Kugler and Hans Leidich of Lumonics Livonia Operations for carrying out the vanadium welds with the Lumonics $2 \mathrm{~kW}$ Nd:YAG laser and Bob Strain at Argonne for the vanadium weld profiles.

\section{References}

1. Mazumder, J. (July, 1982). Laser welding: state of the art review. J. Metals. 16-24.

2. Sakamoto, H., Shibata, K. and Dausinger, F (October, 1992). Laser welding of different aluminum alloys. Proceedings of Laser Materials Processing Symposium (ICALEO'92), Orlando, Florida. 523-528.

3. Rapp, J., Beck, M., Dausinger, F. and Hügel, H. (September, 1994). Fundamental approach to the laser weld ability of aluminum and copper alloys. ECLAT'94. Proc. 5rd European Conf. On Laser Treatment of Materials, Bremen-Vegesack, Germany. 313-325.

4. Mehmetli, B. A., Takahashi, K. and Sato, S. (1996). Comparison of aluminum alloy welding characteristics with $1 \mathrm{~kW} \mathrm{CO}$ and $\mathrm{CO}_{2}$ lasers. J. Laser Applications. 8: 25-31.

5. Toulokian, Y. S., Powell, R. W., Ho, C. Y., and Nicolaou, M. C. (1973). Thermal Diffusivity, Thermophysical Properties of Matter, Vol. 10. IFI/Plenum, New York.

6. Toulokian, Y. S., Powell, R. W., Ho, C. Y., and Nicolaou, M. C. (1970). Thermal Conductivity Metallic Elements and Alloys, Thermophysical Properties of Matter, Vol. 1. IFI/Plenum, New York.

7. Nonhof, C. J. (1988). Material processing with Nd-lasers. Electrochemical Publications, Ayr, Scotland.

8. Grigoryants, A. G. (1994). Basics of Laser Material Processing. Mir Publishers, Moscow. 
9. Prokhorov, A. M., Konov, V., Ursu, I., and Mihailescu, I. N. (1990). Laser Heating of Metals. Adam Hilger. New York.

10. Huittner, B. (1994). Optical Properties of Polyvalent Metals in the Solid and Liquid State: Aluminum. J. Phys. Condensed Matter. 6: 2459-2474.

11. Guizzetti, G. and Piaggi, A. (1991). Vanadium in Handbook of Optical Constants of Solids II. E. D. Palik. Academic Press, New York.

12. Stern, G. (September, 1990). Absorptivity of $\mathrm{cw} \mathrm{CO}_{2}, \mathrm{CO}$ and YAG -laser beams by different metallic alloys. ECLAT'90. Proc. 3rd European Conf. On Laser Treatment of Materials, Erlangen, Germany. 25-35.

13. Aluminum and Aluminum Alloys. (1994). ASM Specialty Handbook. ASM International, Materials Park. Davis, J. R. Ohio.

14. Rapp, J., Glumann, C., Dausinger, F., and Hugel, H. (1992). Influence of processing parameters and alloy composition on the weld seam in laser welding of aluminum alloys. Proceedings European Conference on Laser Treatment of Materials (ECLAT'92). B. L. Mondike, ed. DGM Informationsgesellschaft Verlag. 99-104.

15. Pak, S. W., Kim, K. H., Kwon, S. Y., and Cho, W. S. A study on the joining technology of aluminum alloy sheets for autobody application. Light Materials for Transportation Systems, (N. J. Kim, ed.). Center for Advanced Aerospace Materials, pp. 643-655, 1993

16. Martukanitz, R. P., Smith, D. J., Armao, F. G., Baldantoni, A. and Pickering, E. R. (February 28-March 3, 1994). Laser beam welding of aluminum alloys for automotive applications. Proceedings of the Society of Automotive Engineers International Congress and Exposition, Detroit, Michigan.

17. Berkmanns, J., Imhoff, R., Behler, K. and Beyer, E. (March 6-7, 1995). Laser welding of aluminum. Automotive Laser Applications Workshop, Dearborn, Michigan.

18. Dausinger, F., Faisst, F., Hack, R., Rapp, J., Hugel, H., and Beck, M. (November 13-16, 1995). Welding of aluminum: challenge and chance for laser technology. Proceedings of Laser Materials Processing Symposium (ICALEO’95), San Diego, California.

19. Martukanitz, R. P., Altshuller, B., Armao, F. G., and Pickering, E. R. (1996). Properties and characteristics of laser beam welds of automotive aluminum alloys. Proceedings of the Society of Automotive Engineers International Congress and Exposition, Warrendale, Pennsylvania.

20. Martukanitz, R. P. and Altshuller, B. (October 14-17, 1996). Laser beam welding of aluminum alloy 5754-0 using a $3 \mathrm{~kW}$ Nd:YAG laser and fiber optic beam delivery. Proceedings of Laser Materials Processing Symposium (ICALEO'96). Southfield, Michigan. 
M98000648

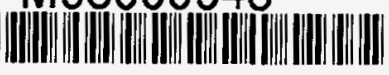

Report Number (14) ANL/TP/CP- $-934+0$ CONF-971149--

Publ. Date (11) 199709

Sponsor Code (18) DOE/EE; DOE/ER , XF

UC Category (19) UC-1500; UC-400, DOE/ER

DOE 